\title{
Checklist for healthy and sustainable communities
}

\author{
Anthony G. Capon ${ }^{\mathrm{A}, \mathrm{B}, \mathrm{D}}$ and Edward J. Blakely \\ A Australian Health Policy Institute, The University of Sydney. \\ ${ }^{\mathrm{B} N a t i o n a l ~ C e n t r e ~ f o r ~ E p i d e m i o l o g y ~ a n d ~ P o p u l a t i o n ~ H e a l t h, ~}$ \\ The Australian National University. \\ ${ }^{\mathrm{C}}$ Planning Research Centre, The University of Sydney. \\ DCorresponding author.Email: acapon@med.usyd.edu.au
}

\begin{abstract}
This paper describes a 10-point checklist for the planning and development of healthy and sustainable communities. The 10 domains in the checklist are essentially physical characteristics of places. Each domain has relevance to the health of people living in the place, and to the sustainability of the environment. The checklist is intended as a tool for those who plan, develop and manage urban environments. Such tools can be valuable for assessing the health and environmental impacts of decisions made by urban and transport planners, and businesses engaged in land development and infrastructure projects.
\end{abstract}

The urban environment is an important determinant of health. ${ }^{1}$ Obesity is a good example of how environmental factors can affect health. Obesity results from an energy imbalance: consuming more energy (food) than is expended through physical activity.

In high-income countries such as Australia, advances in design and engineering during the past 30 years have reduced the need for heavy work and physical activity in daily life. For most people, work is now more sedentary than it was for previous generations. Recreation is also increasingly sedentary. Watching television and playing video games are replacing bike-riding and outdoor games. Increasing amounts of energy from fossil fuels are being used to propel people around their environment (motor vehicles, escalators and lifts.) At the same time, at least as much food is being consumed. There is an increasing reliance on highly processed and convenience foods, which often have high energy content. All of this is making people fat. Further, as a consequence of these changes, excessive carbon dioxide emissions are being produced and this is warming the planet.

Improving the sustainability of urban development will have benefits for human health. ${ }^{2,3}$ In this paper, we argue for the integration of human health considerations with environmental considerations when developing policy for urban and regional planning and sustainability. We present a 10-point checklist as a guide for the development of healthy human habitat. The goal should be to minimise ecological impact while maximising the human experience, including health and well-being. The checklist focuses on characteristics of places rather than people because planners and developers can influence these.

\section{Ten-point checklist for healthy and sustainable communities \\ 1. Outdoor air quality}

Air pollution in Sydney is known to exacerbate asthma. ${ }^{4}$ The main source of outdoor air pollutants in Australian urban environments is motor vehicle emissions. Improved motor vehicle emission controls have reduced emissions for each kilometre travelled; however, the total number of kilometres travelled is increasing. Until there is a reduction in the total number of kilometres travelled, air pollution will remain a health issue in Australian cities.

Urban planning and public health interventions to reduce dependence on motor vehicles and improve air quality include:

- locating jobs, services, schools and shops close to where people live;

- promoting active modes of transport (walking and cycling); and

- providing mass transit options.

\section{Water supply and sanitation}

Ensuring safe drinking water is a traditional public health function. ${ }^{5}$ The drying of the Australian climate has focused attention on water supply and demand. The NSW Government has policies to reduce household water consumption (including restrictions on watering of gardens and promotion of dual-flush toilets and low-flow shower heads). New water supply options are being considered. Recycled water can be safely used in drinking water supplies. Public health professionals have roles in the risk assessment, management and communication about water reuse.

\section{Housing and buildings}

Housing is an important determinant of the ecological footprint of a city. The number of people living in apartments and town houses in Australia has increased exponentially since the 1970s. This has been driven by lifestyle choices, increasing land costs and the trend towards smaller households. The NSW Government has policies to 
reduce energy and water use in new and renovated homes, including Building and Sustainability Index (BASIX) ${ }^{6}$ certification.

Housing and building characteristics with implications for the health of people and the environment include: solar access; indoor air quality; ventilation to minimise the need for air conditioning; reuse of building materials; sustainable materials; avoidance of harmful chemical exposures; on-site reuse of water and alternative sanitation options (such as composting toilets). All communities should have a system equivalent to BASIX to guide new and retro-fit developments at both the building and the neighbourhood levels.

There are benefits from having a mix of housing types and prices in any community, ensuring housing options suitable throughout the life-cycle (including options for those with disabilities). For example, this allows elderly people to move within their community as their housing needs change. They need not leave their established social network.

\section{Food}

A public culture of food brings vitality and conviviality to urban life. ${ }^{7}$ There are health benefits from food shops (fruit and vegetables, meat and fish, daily grocery items) and cafes being in close proximity to where people live. People can walk or cycle to these food outlets, where they can connect with others in their community. This is particularly important for the elderly and disabled people who may not have access to motor vehicles.

Bringing food to people, rather than expecting people to travel by motor vehicle to a regional shopping centre to purchase food, can also reduce carbon dioxide emissions. Such food businesses need a customer base to be financially viable. Locating the businesses on mass transit routes will bring customers to the shops. Economic viability may also be improved by increases in residential density.

Food production in urban areas will be increasingly important as liquid fossil fuels become more expensive. Local production also reduces transport costs. It can enable city dwellers to learn about food production and have contact with nature. Urban agriculture can reduce the intensity of urban heat islands. Growing food in a communal way, in community gardens and city farms, breaks down barriers between people and stimulates a sense of pride in the local environment. ${ }^{8}$ Every jurisdiction should have a food policy to promote local food production and improve access to healthy food. ${ }^{9}$

\section{Local shops and services}

In addition to food shops, there are benefits from having access to other shops and services in our local area, includ- ing primary health care. Shops, services and other destinations can encourage physical activity, social interaction and conviviality. They can also reduce motor vehicle use. However, the emergence of large, stand-alone, regional shopping centers since the 1970s has affected the economic viability of local shops and services. The impact of these changes on our health and well-being warrant further investigation. ${ }^{10}$

\section{Schools and other educational institutions}

Quite apart from what is learnt in schools, including life skills and health literacy, there are health benefits associated with the physical presence of schools within communities. Schools can provide an important social focus in communities. Children, parents and grandparents can develop a social network around the school. Schools also present an unparalleled opportunity to promote children's health. ${ }^{11}$ When schools are located close to children's homes, and when there are safe pathways to the school, children are more likely to walk or cycle to school.

\section{Community spaces}

Spaces (both outdoor and indoor) for recreation and social interaction are a valuable community resource. Parks and community halls are places where groups can meet, play and organise themselves to work together on projects and activities. People who have good access to attractive open spaces are more likely to be physically active. ${ }^{12}$ Governments should place more emphasis on the public domain in Australia, as increasing numbers of people live in apartments and town houses.

Public health workers are advocates for regulation to ensure safety in community spaces; however, care should be taken to avoid over-regulation. Opportunities for children to explore their community unsupervised and take reasonable risks can aid the development of self-esteem and life skills. While rising public indemnity insurance costs are an issue for governments, regulations can reduce fun, informality and spontaneity.

\section{Transport and street connectivity}

Active transport (walking and cycling) is good for our physical and mental health. It also reduces carbon dioxide emissions. People are more likely to walk or cycle if there are destinations of interest in the community, such as shops, services and parks. ${ }^{13}$ Street connectivity is another determinant of the likelihood of walking. ${ }^{2}$ Safe pathways to walk and cycle are essential. Pathways should be well maintained and appropriately lit to reduce the likelihood of slips, trips and other injuries. It is not practical to walk or cycle to work if the job is a long way from home.

Mass transit is good public policy. It is good for health (because it is possible to walk to the bus, tram or train stop), good for the environment (because it reduces 
carbon dioxide emissions) and good for business (because it reduces the cost of traffic congestion.) Mass transit is particularly good for young people, the elderly and the disabled, who may not have access to a motor vehicle.

\section{Communication technology}

Modern communication technologies are essential urban infrastructure. The telephone (whether fixed-line or mobile) connects people with a social network and with work and business opportunities. High-speed internet services enable access to information for work, education and recreation. It is now possible to order a wide range of food and other products via the internet for home delivery, which is of particular value for disabled people. Care has to be taken to ensure that home delivery does not compromise the social and physical activity that accompanies shopping trips.

\section{Economy and employment}

Historically, there was a public health imperative to separating residential areas from employment zones in cities. In particular, industrial point-sources of air pollution were adversely affecting health. In post-industrial societies such as Australia, this is no longer the case. Arguably, there are now public health and environmental imperatives to reintegrate life and work. If people live close to where they work, there can be benefits to their health and the health of the environment. Long commuting times can be a source of stress, can adversely affect health and increase carbon dioxide emissions.

Local economic development is a tool to create locally based jobs. Each community needs to find ways that it can incubate new ideas and new jobs. Communities should have local job generation programs and measure job creation as a central tenet of community well-being not simply the number of people employed. ${ }^{14}$

\section{Implications for the health of people and the health of the environment}

The 10 domains in the checklist are essentially physical attributes of places. These attributes affect our health by influencing:

- levels of physical activity;

- food choices;

- safety and sense of security;

- sound and noise exposure;

- thermal exposure (heat and cold);

- exposure to air and water pollutants and contaminated land;

- access and participation (especially for youth, disabled people, elderly);

- social connection;

- conviviality;

- opportunities for contact with nature; and
- time use (commuting, with family, for recreation, in community).

Similarly, these 10 attributes of places affect the health of the environment through:

- energy consumption;

- water consumption;

- other resource requirements;

- ecosystem and biodiversity impacts;

- carbon dioxide and other greenhouse gas emissions; and

- the production of other pollutants and waste.

\section{Discussion}

This checklist for healthy and sustainable communities demonstrates the diverse range of factors in our urban environment that affect our health. Each of the items on the checklist is in some way interdependent on other items. This means we need to consider the urban environment as a system. The checklist could be further developed as a policy and planning tool for urban planners, sustainability planners and public health practitioners. It might also be developed as an audit tool for the land development industry.

Human health impacts (positive and negative) should be accounted for in the planning, development and management of our urban environments. Equity-focused, health impact assessments provide a framework to improve decision making. ${ }^{15}$ Urban planners make many decisions every day and not all of these can be subject to health impact assessment. There is a case for strengthening the way human health is considered in education programs in urban planning. Similarly, there is a case for strengthening public health education programs by including urban planning in the curriculum. Joint training programs for the existing planning and public health workforce should be encouraged.

There is no ideal urban environment. The circumstances of individuals, such as age, family relationships, health status, employment options and recreational interests will determine the suitability of urban environments. In choosing where to live (whether renting or buying), there will be trade-offs. Careful consideration should be given to resources available in the local area. This will reduce the need to travel and this in turn will reduce carbon dioxide emissions.

\section{Conclusion}

Planning, developing and managing our urban environments more wisely will benefit health and improve environmental outcomes. Environmental concerns are currently at the top of the political agenda both in Australia and internationally. It is imperative that we move beyond the current high-consumption phase of human history to a 
biosensitive phase, ${ }^{16}$ where human activities are in balance with nature. To ensure a successful transition, it is essential that considerations of the health of people are integrated with those of the environment.

\section{Acknowledgement}

This work was enabled by financial support from the Oxford Health Alliance (http://www.oxha.org).

\section{References}

1. Galea S, Vlahov D. Urbanization. In: Frumkin H, editor Environmental health: from global to local. San Francisco: Jossey-Bass, 2005. pp. 387-413.

2. Frumkin H, Frank L, Jackson R. Urban sprawl and public health. Designing, planning and building for healthy communities. Washington: Island Press, 2004.

3. Smart Growth America. Washington: Smart Growth America. Available at http://www.smartgrowthamerica.org/ [Verified 22 April 2007].

4. Jalaludin B. Cars, trucks and buses, the urban environment and ambient air pollution - what's the connection? In: Johnson C, editor. Healthy environments. Sydney: Government Architect's Publications, 2004. pp. 18-25.

5. Cowie C. Water quality. In: Johnson C, editor. Healthy environments. Sydney: Government Architect's Publications, 2004. pp. 26-35.

6. NSW Department of Planning. BASIX - Building Sustainability Index. Available at http://www.basix.nsw.gov.au/ information/index.jsp [Verified 9 April 2007].
7. Franck KA. The city as dining room, market and farm. Architectural Design 2005; 75: 5-10. doi:10.1002/ad.70

8. Doron G. Urban agriculture: small, medium, large. Architectural Design 2005; 75: 52-9. doi:10.1002/ad.76

9. Webb K, King L. Food, nutrition and the built environment. In: Johnson C, editor. Healthy environments. Sydney: Government Architect's Publications, 2004. pp. 46-55.

10. Dixon J. Adding value(s): a cultural economy analysis of supermarket efforts. In: Germov J, Williams L, editors. A sociology of food and nutrition: the social appetite. 2nd Edn. New York: Oxford University Press, 2004. pp. 96-115.

11. Frumkin H, Geller R, Rubin IL, Nodvin J, editors. Safe and healthy school environments. New York: Oxford University Press, 2006.

12. Giles-Corti B, Donovan RJ. Relative influences of individual, social environmental, and physical environmental correlates of walking. Am J Public Health 2003; 93: 1583-9.

13. Owen N, Humpel N, Leslie E, Bauman A, Sallis JF. Understanding environmental influences on walking: review and research agenda. Am J Prev Med 2004; 27: 67-76. doi:10.1016/j.amepre.2004.03.006

14. Blakely EJ, Bradshaw TK. Planning local economic development: theory and practice. 3rd Edn. Thousand Oaks: Sage Publications, 2002.

15. Harris E. Contemporary debates in health impact assessment: What? Why? When? N S W Public Health Bull 2005; 16: $107-8$.

16. Boyden S. The biology of civilisation. Sydney: UNSW Press, 2004. 